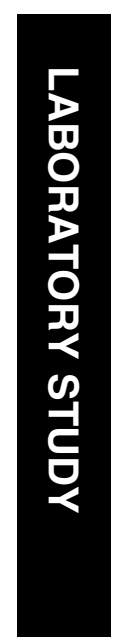

\title{
Protein carbonyl levels in the aqueous humour and serum of patients with pseudoexfoliation syndrome
}

${ }^{1}$ Department of Ophthalmology, Medical School, Fatih University, Ankara, Turkey

${ }^{2}$ Ankara Training and Research Hospital, Department of Ophthalmology, Ankara, Turkey

${ }^{3}$ Department of Biochemistry and Clinical Biochemistry, Medical School, Zonguldak Karaelmas University, Zonguldak, Turkey

Correspondence: R Yagcı, Fakülteler M Keskin S 9/3 Cebeci, 06590 Çankaya/ Ankara, Turkey Tel: +90 31231990 10; Fax: + 903122213276 E-mail: ramazanyagci@ yahoo.com

Received: 3 September 2006

Accepted in revised form: 4 January 2007

Published online: 9 February 2007

There are no any proprietary interests or research funding

\begin{abstract}
Purpose Protein oxidation is an oxidative stress marker and the oxidation of proteins is analysed by measuring the carbonyl groups. Protein oxidation can have a role in the physiopathology of pseudoexfoliation (PEX) syndrome. The aim of this study was to investigate the protein oxidation in the aqueous humour and serum of cataract patients with and without PEX.

Methods A multicenter study was carried out. Aqueous humour and serum samples were collected from patients who underwent routine cataract surgery. Patients were divided into PEX $(n=29)$ and control $(n=27)$ groups. Patients had no elevated intraocular pressure or glaucoma. Spectrophotometer was used to measure protein carbonyl (PC) levels in the samples.

Results Mean PC concentration in the PEX aqueous $(2.18 \pm 1.51 \mathrm{nmol} / \mathrm{l})$ and serum $(119.62 \pm 13.2 \mathrm{nmol} / \mathrm{l})$ samples was significantly higher than that measured in the control aqueous $(1.31 \pm 0.47 \mathrm{nmol} / \mathrm{l})$ and serum $(105.85 \pm$ $11.76 \mathrm{nmol} / \mathrm{l})$ samples, respectively $(P<0.001)$. Conclusion The increased PC levels in the aqueous humour and serum of PEX patients suggest that protein oxidation may play a role in the physiopathology of PEX.
\end{abstract}

Eye (2008) 22, 128-131; doi:10.1038/sj.eye.6702751; published online 9 February 2007

Keywords: protein carbonyl; aqueous humour; oxidative stress; protein oxidation; pseudoexfoliation

\section{Introduction}

Pseudoexfoliation (PEX) syndrome is a clinically significant systemic disorder of the
R Yağcl' ${ }^{1}$ I Ersözz ${ }^{2}$ M Erdurmuş ${ }^{1}$, A Gürel ${ }^{3}$ and S Duman ${ }^{2}$ extracellular matrix, which represents the most common identifiable cause of open angle glaucoma. ${ }^{1,2}$ Also, PEX is associated with accelerated cataract progression and a clearly increased number of surgical complications such as high IOP, zonular and posterior capsule rupture, and weak pupil dilatation during cataract surgery. Therefore, it is clinically important. PEX is age-related and characterized by production and progressive accumulation of a fibrillar material in ocular and systemic tissues and affects the entire anterior segment structure of the eye. The precise biochemical nature of the exfoliative material, the pathogenetic mechanism responsible for the development, and pathophysiology causing to elevate intraocular pressure in PEX remain unclear.

The eye is an exceptional organ because of its continuous exposure to environmental chemicals, radiation, and atmospheric oxygen. Those oxidative stress mechanisms in ocular tissues have been hypothesized to play a role in diseases such as cataract, glaucoma, uveitis, and age-related macular degeneration. ${ }^{3}$ Recent studies on aqueous humour composition in PEX have provided evidence that oxidative stress may play a major role in the pathogenesis of PEX. ${ }^{4,5}$

Protein oxidation is a useful marker to evaluate oxidative stress in vivo. Protein carbonyl (PC) content is the most general and well-used biomarker of severe oxidative protein damage. PC has a major advantage over lipid peroxidation products as markers of oxidative stress: oxidized proteins are generally more stable. PC form early and circulate in the blood for longer periods, compared with other parameters of oxidative stress, such as glutathione disulphide and malondialdehyde. In fact, elevated levels of PC are generally a sign 
of oxidative stress and moreover a sign of diseasederived protein dysfunction. ${ }^{6,7}$

Our study was designed to compare PC levels in the aqueous humour and serum of patients undergoing cataract surgery with and without PEX and investigate the possible role of protein oxidation in the development of PEX.

\section{Materials and methods}

Multicentre study was undertaken. A total of 56 aqueous and serum samples were collected: 29 from cataract patients with PEX (mean age, 66.9 \pm 8.3 ) years) and 27 from cataract patients without PEX (mean age, $63.9 \pm 8.1$ ) years). All patients underwent a complete ophthalmic examination and were examined before surgery after pupillary dilatation for the presence of exfoliation material. Only patients who exhibited exfoliation material upon the lens or pupil were included. Patients with glaucoma or elevated intraocular pressure (defined as intraocular pressure higher than $20 \mathrm{~mm} \mathrm{Hg}$ ), using topical medication and any ophthalmic pathology other than PEX or senile cataract were excluded from the study. Informed consent was obtained from patients. The study was approved by the locally ethic committee and followed the Declaration of Helsinki for research involving human subjects.

Aqueous humour samples were collected from patients who underwent routine cataract surgery. A small amount of aqueous humour (100-200 $\mu \mathrm{l})$ was aspirated at the beginning of phacoemulsification cataract surgery by limbal paracentesis. A 30-gauge needle attached to a tuberculin microsyringe was used to aspirate the aqueous humour from the central pupillary area. The samples were immediately stored at $-80^{\circ} \mathrm{C}$ until analysed. Serum specimens were also collected from patients before surgery for measurement of PC levels.

Oxidative damage to proteins was assessed by the determination of carbonyl groups based on the reaction with dinitrophenylhydrazine (DNPH), as previously described. ${ }^{8}$ Briefly, proteins were precipitated by the addition of $20 \%$ trichloroacetic acid and redissolved in $10 \mathrm{mM}$ DNPH, and the absorbance was read at $370 \mathrm{~nm}$. The results were calculated using the extinction coefficient of 22000 for aliphatic hydrazone. Results are given as $\mathrm{nmol} / \mathrm{l}$.

All statistical analyses were carried out using SPSS statistical software (SPSS for windows, version 11.0). All data were presented in mean $( \pm)$ SDs. Differences in measured parameters between two groups were analysed by independent samples $t$-test. The differences were considered significant when the probability was less than 0.05 .

\section{Results}

The mean concentration of $\mathrm{PC}$ in the aqueous humour of PEX group $(2.18 \pm 1.51 \mathrm{nmol} / \mathrm{l})$ was found to be significantly higher than that of control patients $(1.31 \pm 0.47 \mathrm{nmol} / \mathrm{l}, P<0.001$; Figure 1). The mean concentration of PC in the serum of PEX $(119.62 \pm 13.2 \mathrm{nmol} / \mathrm{l})$ significantly increased compared to controls (105.85 $\pm 11.76 \mathrm{nmol} / \mathrm{l}, P<0.001$; Figure 2).

\section{Discussion}

In the present study, the human aqueous humour and serum PC levels were measured in patients with PEX. We documented a significantly higher concentration of PC in the aqueous humour and serum of patients with PEX compared to control.

One of the greatest challenges in oxidation research today is the determination of oxidative stress in vivo. Because proteins are ubiquitous in all cells and tissues and are susceptible to oxidative modification, they can serve as useful markers of oxidative stress. Oxidized proteins have been detected in numerous disease conditions. Compared to measuring products of lipid peroxidation and DNA oxidative base modifications, proteins offer some advantages as markers of oxidative stress. Proteins have unique biological functions, so there

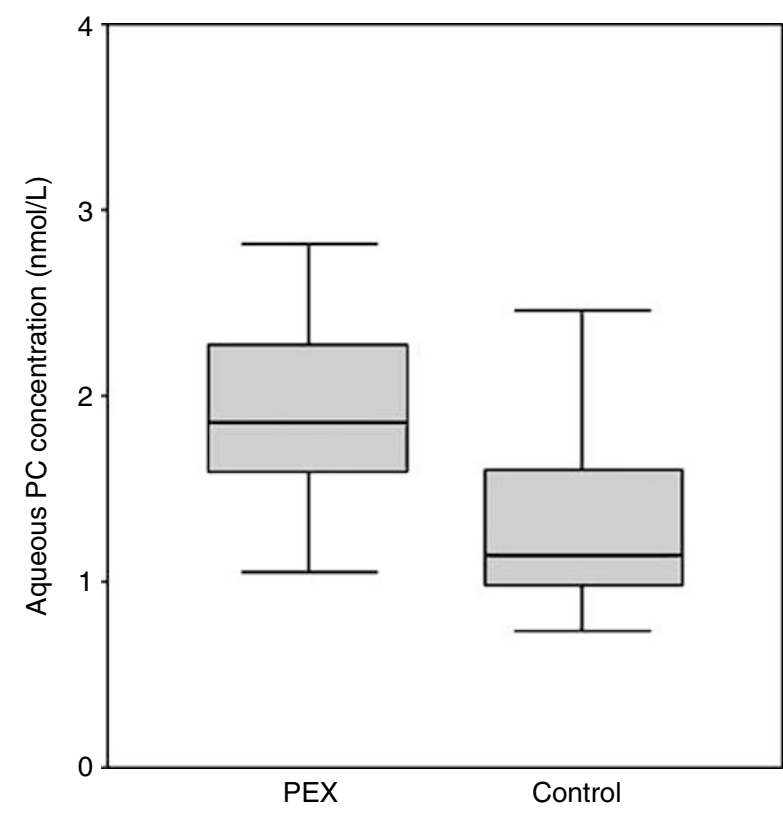

Figure 1 PC concentration in the aqueous humour of patients with and without PEX syndrome. The mean \pm SD concentration of $\mathrm{PC}$ in the aqueous humour from patients with PEX $(2.18 \pm 1.51 \mathrm{nmol} / \mathrm{l})$ was significantly higher than that of control patients $(1.31 \pm 0.47 \mathrm{nmol} / \mathrm{l}$; $P<0.001)$ (PC: protein carbonyl, PEX: pseudoexfoliation, SD: standard deviation). 


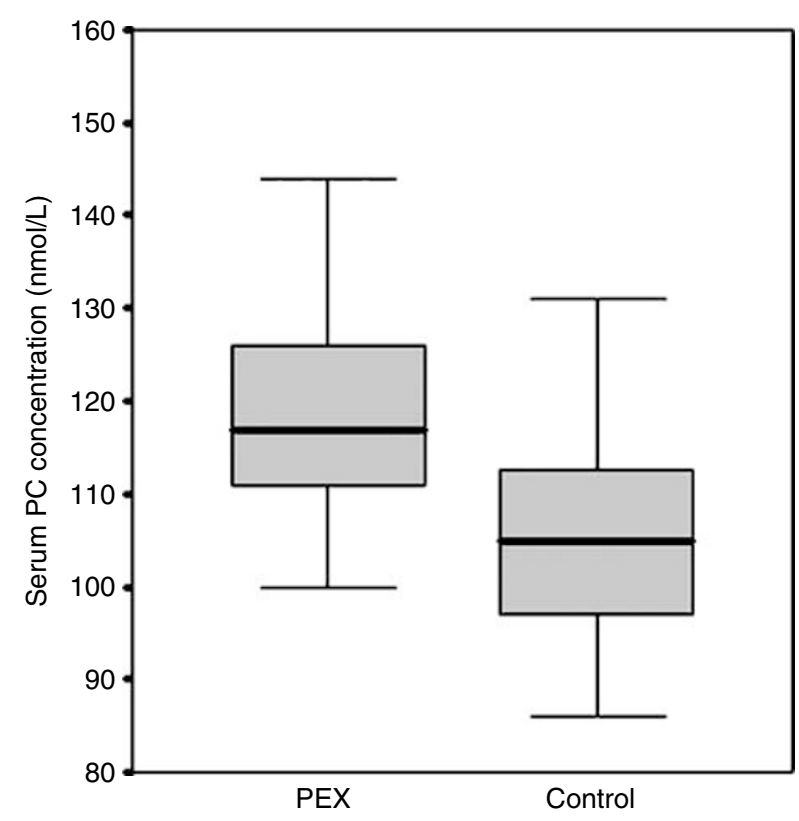

Figure 2 PC concentration in the serum of patients with and without PEX syndrome. The mean \pm SD concentration of PC in the serum from patients with PEX $(119.62 \pm 13.2 \mathrm{nmol} / \mathrm{l})$ was significantly higher than that of control patients $(105.85 \pm 11.76 \mathrm{nmol} / \mathrm{l} ; \quad P<0.001)$ (PC: protein carbonyl, PEX: pseudoexfoliation, SD: standard deviation).

are unique functional consequences resulting from their modification. For example, oxidative modification of enzymes has been shown to inhibit a wide array of enzyme activities. ${ }^{9,10}$ Modification of structural proteins can also lead to a loss of function. Products of protein oxidative modification are relatively stable and there are sensitive assays available for their detection; thus, from a purely technical perspective, they serve as suitable markers for oxidative stress. ${ }^{6,7}$

PC content is the most general indicator and by far the most commonly used marker of protein oxidation. Carbonyls are relatively difficult to induce compared with methionine sulphoxide and cysteinyl derivatives, and might therefore indicate a more severe oxidative stress. Indeed, elevated levels of PC are generally a sign not only of oxidative stress but also of disease-derived protein dysfunction. $6,7,11,12$

There are several reports on relation between oxidative stress and PEX., 4,13,14 The aqueous level of 8-

isoprostaglandin F2a (8-IsoPGF2a), a marker of oxidative stress, was found to be five times higher in PEX than in control samples and its increased concentration correlated well with the reduction in ascorbic acid concentration in the same sample. ${ }^{5}$ Yilmaz et $a l^{13}$ indicated that antioxidant, serum vitamin $\mathrm{C}$ concentrations were much lower and malondialdehyde concentrations were much higher in PEX subjects, reflecting free radical damage to lipid peroxides. Moreover, in our previous study, we had detected increased protein oxidation in the serum of patients with PEX. ${ }^{15}$ In the present study, we showed increased oxidative stress in both aqueous and serum of patients with PEX.

Growth factors, ${ }^{16}$ metalloproteinases, ${ }^{17}$ and endothelin 1 (ET-1) ${ }^{18,19}$ can be activated by free radicals.

Furthermore, growth factors, metalloproteinases, and ET-1 have been shown to be involved in the pathobiology of PEX. ${ }^{20-22}$ Some studies have suggested that ET-1 promotes synthesis and/or turnover of extracellular matrix that has a role in the pathogenesis of PEX. ${ }^{23,24}$ In addition, increased concentrations of transforming growth factor beta 1 (TGF- $\beta 1$ ), a powerful modulator of extracellular matrix formation, ${ }^{25}$ have been identified in the aqueous humour of patients with $\mathrm{PEX}^{26}$ and increased TGF- $\beta 1$ synthesis has been related with increased levels of reactive oxygen species. ${ }^{27}$ Therefore, increased oxidative stress might take part in the PEX pathobiology by increasing growth factors, metalloproteinases, ET-1, and TGF- $\beta 1$. We have showed that protein oxidation, a useful oxidative stress marker, increased in PEX. Furthermore, oxidative alteration of enzymes can change their activities ${ }^{9,10}$ and increased levels of PC indicate that protein dysfunction. ${ }^{11,12}$ As a result of these changes, synthesis and composition of extracellular matrix may alter and abnormal extracellular material that is the characteristic of PEX accumulates in the eye.

There is experimental evidence demonstrating the protective effects of antioxidants in in vitro models (e.g., neurodegeneration) and in some animal models. The potential involvement of reactive oxygen species in the pathogenesis of several diseases suggests that free-radical scavengers and antioxidants might have therapeutic uses. ${ }^{7}$ Antioxidant therapy may offer potential therapeutic avenues for controlling PEX-related ocular morbidity.

In conclusion, we have documented significantly increased aqueous humour and serum PC concentrations in patients with PEX compared with that of control patients without PEX. The findings suggest a pathophysiologic role for protein oxidation in PEX. Further research is required to clarify the role of protein oxidation and oxidative stress in the development PEX, the progression to pseudoexfoliative glaucoma.

\section{References}

1 Naumann GO, Schlotzer-Schrehardt U, Kuchle M. Pseudoexfoliation syndrome for the comprehensive ophthalmologist. Intraocular and systemic manifestations. Ophthalmology 1998; 105: 951-968. 
2 Ritch R, Schlotzer-Schrehardt U. Exfoliation syndrome. Surv Ophthalmol 2001; 45: 265-315.

3 Ohia SE, Opere CA, LeDay AM. Pharmacological consequences of oxidative stress in ocular tissues. Mutat Res 2005; 579: 22-36.

4 Koliakos GG, Konstas AG, Schlotzer-Schrehardt U, Bufidis $\mathrm{T}$, Georgiadis N, Ringvold A. Ascorbic acid concentration is reduced in the aqueous humor of patients with exfoliation syndrome. Am J Ophthalmol 2002; 134: 879-883.

5 Koliakos GG, Konstas AG, Schlotzer-Schrehardt U, Hollo G, Katsimbris IE, Georgiadis N et al. 8-Isoprostaglandin F2a and ascorbic acid concentration in the aqueous humour of patients with exfoliation syndrome. Br J Ophthalmol 2003; 87: 353-356.

6 Shacter E. Quantification and significance of protein oxidation in biological samples. Drug Metab Rev 2000; 32: 307-326.

7 Dalle-Donne I, Giustarini D, Colombo R, Rossi R, Milzani A. Protein carbonylation in human diseases. Trends Mol Med 2003; 9: 169-176.

8 Levine RL, Garland D, Oliver CN, Amici A, Climent I, Lenz AG et al. Determination of carbonyl content in oxidatively modified proteins. Methods Enzymol 1990; 186: 464-478.

9 Stadtman ER. Metal ion-catalyzed oxidation of proteins: biochemical mechanism and biological consequences. Free Radical Biol Med 1990; 9: 315-325.

10 Fucci L, Oliver CN, Coon MJ, Stadtman ER. Inactivation of key metabolic enzymes by mixed-function oxidation reactions: possible implication in protein turnover and ageing. Proc Natl Acad Sci USA 1983; 80: 1521-1525.

11 Berlett BS, Stadtman ER. Protein oxidation in aging, disease, and oxidative stress. J Biol Chem 1997; 272: 20313-20316.

12 Beal MF. Oxidatively modified proteins in aging and disease. Free Radic Biol Med 2002; 32: 797-803.

13 Yilmaz A, Adigüzel U, Tamer L, Yildirim $\mathrm{O}, \mathrm{Oz} \mathrm{O}$, Vatansever $\mathrm{H}$ et al. Serum oxidant/antioxidant balance in exfoliation syndrome. Clin Exp Ophthalmol 2005; 33: 63-66.

14 Schlotzer-Schrehardt U, Naumann GO. Ocular and systemic pseudoexfoliation syndrome. Am J Ophthalmol 2006; 141: 921-937.

15 Yagci R, Gurel A, Ersoz I, Keskin UC, Hepsen IF, Duman S et al. Oxidative stress and protein oxidation in pseudoexfoliation syndrome. Curr Eye Res 2006; 31: 1029-1032.
16 Barcellos-Hoff MH, Dix TA. Redox-mediated activation of latent transforming growth factor-beta 1. Mol Endocrinol 1996; 10: 1077-1083.

17 Cejkova J, Lojda Z. The appearance of active plasminogen activator of urokinase type (u-PA) in the rabbit anterior eye segment irradiated by UVB rays. A histochemical and biochemical study. Acta Histochem 1995; 97: 257-262.

18 Kahler J, Ewert A, Weckmuller J, Stobbe S, Mittmann C, Koster $\mathrm{R}$ et al. Oxidative stress increases endothelin-1 synthesis in human coronary artery smooth muscle cells. J Cardiovasc Pharmacol 2001; 38: 49-57.

19 Yura T, Fukunaga M, Khan R, Nassar GN, Badr KF, Montero A. Free-radical-generated F2-isoprostane stimulates cell proliferation and endothelin-1 expression on endothelial cells. Kidney Int 1999; 56: 471-478.

20 Koliakos GG, Konstas AG, Triantos A, Ritch R. Increased growth factor activity in the aqueous humour of patients with exfoliation syndrome. Graefes Arch Clin Exp Ophthalmol 2000; 238: 491-495.

21 Schlotzer-Schrehardt U, Lommatzsch J, Kuchle M, Konstas AG, Naumann GO. Matrix metalloproteinases and their inhibitors in aqueous humor of patients with pseudoexfoliation syndrome/glaucoma and primary open-angle glaucoma. Invest Ophthalmol Vis Sci 2003; 44: 1117-1125.

22 Koliakos GG, Konstas AG, Schlotzer-Schrehardt U, Hollo G, Mitova D, Kovatchev D et al. Endothelin-1 concentration is increased in the aqueous humour of patients with exfoliation syndrome. Br J Ophthalmol 2004; 88: 523-527.

23 Guarda E, Katwa LC, Myers PR, Tyagi SC, Weber KT. Effects of endothelins on collagen turnover in cardiac fibroblasts. Cardiovasc Res 1993; 27: 2130-2134.

24 Xu SW, Denton CP, Dashwood MR, Abraham DJ, Black CM. Endothelin-1 regulation of intercellular adhesion molecule-1 expression in normal and sclerodermal fibroblasts. $J$ Cardiovasc Pharmacol 1998; 31(Suppl 1): S545-547.

25 Border WA, Noble NA. Transforming growth factor beta in tissue fibrosis. N Engl J Med 1994; 331: 1286-1292.

26 Schlotzer-Schrehardt U, Zenkel M, Kuchle M, Sakai LY, Naumann GO. Role of transforming growth factor-beta1 and its latent form binding protein in pseudoexfoliation syndrome. Exp Eye Res 2001; 73: 765-780.

27 Weiss MF, Scivittaro V, Anderson JM. Oxidative stress and increased expression of growth factors in lesions of failed hemodialysis access. Am J Kidney Dis 2001; 37: 970-980. 